\title{
Enhancement of Monascus yellow pigments production by activating the CAMP signalling pathway in Monascus purpureus HJ11
}

\author{
Jiawei Liu', Yun Du ${ }^{1}$, Hongmin $\mathrm{Ma}^{2}$, Xiaolin $\mathrm{Pei}^{3}$ and $\mathrm{Mu} \mathrm{Li}{ }^{1^{*}} \mathbb{D}$
}

\begin{abstract}
Background: Monascus azaphilone pigments (MonAzPs), which were produced by Monascus species, have been used as important food colorant and food supplements for more than one billion people during their daily life. Moreover, MonAzPs recently have received more attention because of their diverse physiological activities. However, the high microbial production of MonAzPs is still not always guaranteed. Herein, the aim of this study was to develop an efficient biotechnological process for MonAzPs production.

Results: In this study, exogenous cyclic adenosine monophosphate (cAMP) treatment not only induced MonAzPs production, but also stimulated the expression of a cAMP phosphodiesterase gene, named as mrPDE, in M. purpureus HJ11. Subsequently, MrPDE was identified as a CAMP phosphodiesterase by in vitro enzymatic reaction with purified enzyme. Further, a gene knockout mutant of mrPDE was constructed to verify the activation of cAMP signalling pathway. Deletion of mrPDE in M. purpureus HJ11 improved CAMP concentration by 378\% and enhanced PKA kinase activity 1.5 -fold, indicating that activation of CAMP signalling pathway was achieved. The $\triangle m r P D E$ strain produced MonAzPs at $8563 \mathrm{U} / \mathrm{g}$, with a 2.3-fold increase compared with the WT strain. Moreover, the NAPDH/NADP ${ }^{+}$ratio of the $\triangle m r P D E$ strain was obviously higher than that of the wild type strain, which led to a higher proportion of yellow MonAzPs. With fed-batch fermentation of the $\triangle m r P D E$ strain, the production and yield of MonAzPs achieved $332.1 \mathrm{U} /$ $\mathrm{mL}$ and $8739 \mathrm{U} / \mathrm{g}$.
\end{abstract}

Conclusions: A engineered M. purpureus strain for high MonAzPs production was successfully developed by activating the CAMP signalling pathway. This study not only describes a novel strategy for development of MonAzPs-producing strain, but also provides a roadmap for engineering efforts towards the production of secondary metabolism in other filamentous fungi.

Keywords: Monascus purpureus, Monascus azaphilone pigments, cAMP signaling pathway, cAMP phosphodiesterase, Gene knockout, Fed-batch fermentation

*Correspondence: limu@mail.hzau.edu.cn

${ }^{1}$ Hubei International Scientific and Technological Cooperation Base of Traditional Fermented Foods, Key Laboratory of Environment Correlative Dietology, College of Food Science and Technology, Huazhong Agricultural University, Hubei Province, Wuhan 430070, China

Full list of author information is available at the end of the article

\section{Background}

Monascus azaphilone pigments (MonAzPs) are large group of secondary metabolites produced via polyketide biosynthesis mainly by Monascus spp. strains [1, 2]. MonAzPs have been generally classified into yellow, orange, and red pigment subclasses on the basis of color $[3,4]$. MonAzPs have been extensively used as natural food coloring agents and food supplements for more than one billion people $[5,6]$. These pigments have also been

(c) The Author(s) 2020. This article is licensed under a Creative Commons Attribution 4.0 International License, which permits use, sharing, adaptation, distribution and reproduction in any medium or format, as long as you give appropriate credit to the original author(s) and the source, provide a link to the Creative Commons licence, and indicate if changes were made. The images or other third party material in this article are included in the article's Creative Commons licence, unless indicated otherwise in a credit line to the material. If material is not included in the article's Creative Commons licence and your intended use is not permitted by statutory regulation or exceeds the permitted use, you will need to obtain permission directly from the copyright holder. To view a copy of this licence, visit http://creativecommons.org/licenses/by/4.0/. The Creative Commons Public Domain Dedication waiver (http://creativecommons.org/publicdomain/zero/1.0/) applies to the data made available in this article, unless otherwise stated in a credit line to the data. 
found to exhibit a wide range of biological activities, such as anti-cancer, anti-inflammation, and anti-obesity [7-9].

The annual MonAzPs production has been estimated to exceed 20,000 metric tons in China alone [6]. Many approaches have been applied for improvement of MonAzPs production, such as mutation breeding, process control, genetic engineering and extraction fermentation [10-14]. Among them, the Monascus kaoliang mutation strain produced azaphilone derivatives, such as monascusones A and B, with potential application in sunscreen cosmetics [10]. The highest MonAzPs production was achieved with $211 \mathrm{U} / \mathrm{mL}$ using a mutant $M$. purpureus strain M183 in liquid-state (submerged) fermentation [15]. However, these microbial productions of MonAzPs still do not fully meet the demand for cost-effective production.

The cyclic adenosine monophosphate (cAMP) is a second messenger in eukaryotic and prokaryotic cells [16]. cAMP was produced by adenylyl cyclase (AC) with ATP as substrate [17]. The concentrations of cAMP in microbial cells directly governed the activity of protein kinase A (PKA) and indirectly modulated metabolic and transcriptional processes (Fig. 1) [18-20]. The cAMP-PKA pathway is important for various growth and developmental processes in different fungi [21]. Furthermore, cAMP signalling has been implicated in regulating secondary metabolisms in several fungi, including Fusarium graminearum and Aspergillus species [22, 23]. It has been reported that MonAzPs production in M. ruber M7 was improved by addition of exogenous cAMP to the culture medium [24].

In cAMP metabolism, it is rapidly and continuously converted into adenosine $5^{\prime}$ monophosphate (5'-AMP) by cAMP phosphodiesterases (PDEs) [25]. Reduction or elimination of PDE activity could improve cAMP concentration, which led to regulation of secondary metabolites (SMs) biosynthesis [26, 27]. PDE-knockout mutant of Aspergillus flavus CA14PTs exhibited twofold higher cAMP level and SM aflatoxin production [28]. In F. graminearum, Pde2 was found to be the major PDE responsible for negative regulation of deoxynivalenol production [23]. On the basis of these literatures, it was speculated that knockout of PDE gene in Monascus spp. might improve MonAzPs production by increasing cAMP concentration (Fig. 1). However, the PDE gene and its regulation on cAMP in Monascus spp. is still unknown.

In this study, a novel PDE gene, $m r P D E$, from $M$. purpureus strain $\mathrm{HJ} 11$ was identified by in vitro reaction. Then, the mrPDE gene knockout strain was constructed by genetic engineering. The cAMP concentration of $\triangle$ mrPDE strain significantly increased, which resulted in a significant improvement of MonAzPs production.
Further, a high MonAzPs production was achieved by fed-batch fermentation. This study could provide a new insight for development of efficient MonAzPs-producing strain.

\section{Methods}

\section{Strains and plasmids}

Monascus purpureus strain HJ11 was isolated from rice wine starter and preserved in our laboratory. Escherichia coli BL21 (DE3) was used as gene expression host. M. purpureus HJ11 strain was co-incubated with Agrobacterium tumefaciens EHA105, containing recombinant pCAMBIA3300, to obtain deletion mutants. pCAMBIA3300 vector was used as deletion vector and pET30a $(+)$ was used as heterologous gene expression in E. coli BL21 (DE3).

\section{Flask cultivation}

Monascus purpureus strains were pre-cultured in $10 \mathrm{~mL}$ of glucose mineral salt (GM) medium at $30{ }^{\circ} \mathrm{C}, 120 \mathrm{rpm}$ for 5 days to obtain the seed culture (GM medium in g/L: glucose 30, $\left(\mathrm{NH}_{4}\right)_{2} \mathrm{SO}_{4} 5, \mathrm{KH}_{2} \mathrm{PO}_{4} 5, \mathrm{Na}_{2} \mathrm{HPO}_{4} 3$, $\mathrm{MgSO}_{4} 0.1, \mathrm{CaCl}_{2} 0.1, \mathrm{ZnSO}_{4} \cdot 7 \mathrm{H}_{2} \mathrm{O} 0.1, \mathrm{FeSO}_{4} \cdot 7 \mathrm{H}_{2} \mathrm{O} 0.1$, $\mathrm{CoSO}_{4} \cdot 7 \mathrm{H}_{2} \mathrm{O} 0.05, \mathrm{CuSO}_{4} \cdot 5 \mathrm{H}_{2} \mathrm{O} 0.02$, and $\mathrm{MnSO}_{4} \cdot \mathrm{H}_{2} \mathrm{O}$ 0.01 ). The seed culture was inoculated in $50 \mathrm{~mL}$ of GM medium in 250-mL flasks and incubated under same condition for 10 days. When needed, sterile cAMP powder was added to culture medium. The sterile AMP was prepared as following: the cAMP powder (Sigma, Shanghai, China) was dissolved in dd $\mathrm{H}_{2} \mathrm{O}$ to $25 \mathrm{mM}$, and filtered with sterile $0.22 \mu \mathrm{m}$ membrane filter for removing microorganism, and then the resulting solution was lyophilized to obtain sterile cAMP powder. The collected mycelia were dried to a constant weight at $80^{\circ} \mathrm{C}$ to determine DCW.

The fermentation in rice medium was performed as following: $20 \mathrm{~g}$ rice (pre-immersed for $2 \mathrm{~h}$ in water at $30{ }^{\circ} \mathrm{C}$ ), and $50 \mathrm{~mL}$ water were put into a $250-\mathrm{mL}$ Erlenmeyer flask, and mixed well. After sterilization at $121^{\circ} \mathrm{C}$ for $20 \mathrm{~min}, 3 \mathrm{~mL}$ spore solution $\left(2 \times 10^{5} / \mathrm{mL}\right)$ was inoculated, and then incubated at $30{ }^{\circ} \mathrm{C}$ for $5-7$ days. The spore solution was prepared by washing the mycelium, pre-cultivated on agar for 7 days, with Tween- 80 solution $(0.5 \%)$. The fermented rice was dried to a constant weight at $80^{\circ} \mathrm{C}$ and analyzed for pigments.

\section{Heterologous expression and purification of MrPDE}

RNA extraction and cDNA synthesis were performed according to our previous study [29]. The $m r P D E$ gene fragment, Monpu1|448456|e_gw1.142.20.1 (ID number of the JGI database), was cloned from cDNA with specificd esigned primers using PCR reaction. The mrPDE DNA fragment and vector $\mathrm{pET} 30 \mathrm{a}(+)$ were 

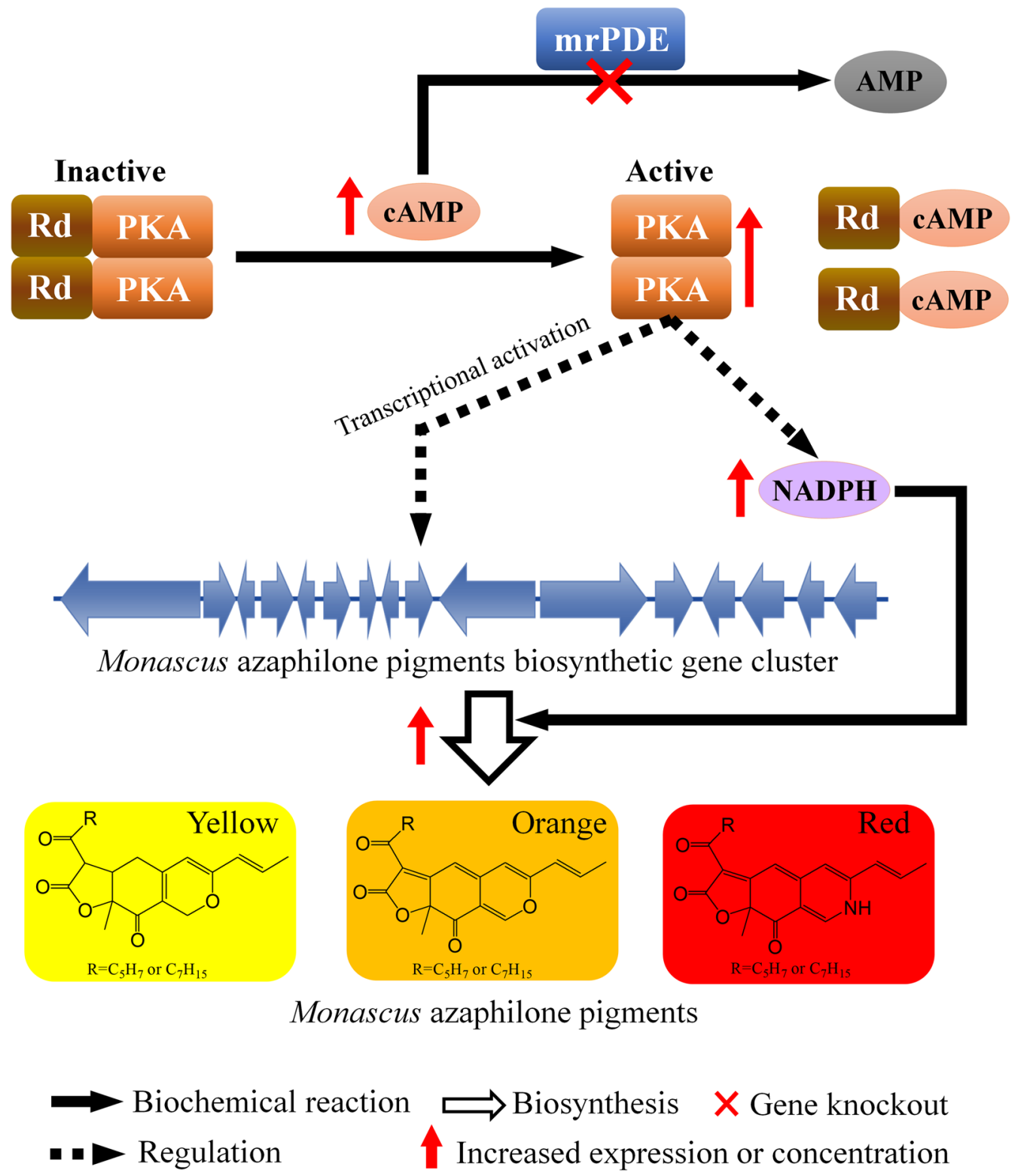

Fig. 1 Regulation of CAMP signalling pathway on the MonAzPs biosynthesis in engineered M. purpureus HJ11. The concentration of CAMP was negatively regulated by MrPDE. PKA, which was activated by CAMP, modulated the expression of MonAzPs biosynthetic gene cluster indirectly. The enzymes from cluster produced MonAzPs. CAMP, cyclic adenosine monophosphate; PKA, protein kinase A; CA, adenylate cyclase

digested by endonucleases EcoRI and HindIII, respectively. The recombinant vector pET30a $(+)-m r P D E$ was constructed with T4 DNA ligase and used for expression of mrPDE. All sequences were confirmed by DNA sequencing. The recombinant vector pET30a $(+)$ mrPDE was transformed into E. coli BL21(DE3) for expression. The resultant $E$. coli strain was inoculated in $100 \mathrm{~mL} \mathrm{LB}$ medium, containing $50 \mu \mathrm{g} / \mathrm{mL}$ kanamycin, in $500-\mathrm{mL}$ flask and incubated at $37{ }^{\circ} \mathrm{C}$ and
$200 \mathrm{rpm}$. Isopropyl- $\beta$-D-thiogalactopyranoside (IPTG) was added to the medium at a final concentration of $0.5 \mathrm{mM}$, when the optical density of culture reached $0.6-1.0$ at $600 \mathrm{~nm}$. Then, the culture was incubated at $18{ }^{\circ} \mathrm{C}$ and $200 \mathrm{rpm}$ for $16 \mathrm{~h}$. The His-tagged mrPDE protein was purified using Nickel-NTA Agarose (Qiagen, Valencia, CA, USA), as described in our previous study and was examined on $12 \%(\mathrm{w} / \mathrm{v})$ SDS-PAGE gel [30]. Protein concentration was estimated by the Bradford method using bovine serum albumin as standard. 


\section{PDE activity detection}

Phosphodiesterase activity was determined using a PDE activity assay kit (Colorimetric) following the manufacturer's instructions (Abcam, Cambridge, United Kingdom) with slight modification [31]. The PDE activities were determined in purified mrPDE and recombinant $E$. coli lysates. The lysates were obtained by disrupting the cells using sonication (W140D, Heat System-Ultrasonics, Inc., NY), followed by centrifugation at $12,000 \times g$ for $10 \mathrm{~min}$ to remove cell debris. One unit of PDE activity for $3^{\prime} 5^{\prime}$-cAMP was defined as the amount of enzyme required to release $1.0 \mu \mathrm{mol} 5^{\prime}$-AMP from $3^{\prime} 5^{\prime}$-cAMP per minute at $30{ }^{\circ} \mathrm{C}$.

\section{PKA activity determination}

Suspended cells were lysed by a high-pressure homogenizer. Cell lysates were incubated at $30^{\circ} \mathrm{C}$ as specified by the protocol of PKA (Protein Kinase A) Colorimetric Activity Kit (Thermo Fisher Scientific). The PKA kinase activity was measured by the colorimetric method at $450 \mathrm{~nm}$ on a spectrophotometer. The PKA kinase activity was calculated using a calibration curve, which was constructed using five PKA standard solutions.

\section{qRT-PCR}

RNA extraction, cDNA synthesis, and qRT-PCR were performed as previous work described [29]. Briefly, total RNA was extracted from mycelial samples, and then checked for purity and integrity. cDNA synthesis was performed using the PrimeScript RT master mix (TaKaRa) according to the manufacturer instruction. qRT-PCR was conducted with a two-step thermal procedure (step $1,95^{\circ} \mathrm{C}$ for $10 \mathrm{~s}$, and step 2,40 cycles of $95^{\circ} \mathrm{C}$ for $3 \mathrm{~s}$ and $60{ }^{\circ} \mathrm{C}$ for $25 \mathrm{~s}$ ) on a 7500 Fast real-time PCR system (Applied Biosystems). The cycle number was used for the quantitation of the expression level. Relative expression level of target cDNA was obtained by the $2^{-\triangle \Delta C T}$ method via normalization to $\beta$-actin (GenBank accession no. AJ417880).

\section{cAMP concentration measurement}

The cAMP concentration was determined according to the previous work with modification [32]. M. purpureus HJ11 strains were cultivated in GM medium at $30{ }^{\circ} \mathrm{C}$. Fresh mycelia were harvested, frozen and lyophilized and ground into powder using liquid nitrogen. The powder sample was kept in chilled $6 \%(\mathrm{w} / \mathrm{v})$ trichloro acetic acid (TCA) solution and incubated for for $20 \mathrm{~min}$. After centrifugation of the mixture at $3500 \times g$ at $4{ }^{\circ} \mathrm{C}$ for $20 \mathrm{~min}$, the supernatant was extracted 3 times with 10 volumes of diethyl ether to remove TCA residues. The resulting extract was dried before further analysis. The cAMP levels were quantified using cAMP Enzyme Immunoassay Kit, Direct (Sigma-Aldrich, St. Louis, MO) following the manufacturer's instructions. In total, assay was repeated three times independently with three biological replicates for each strain.

\section{$\mathrm{NADPH} / \mathrm{NADP}^{+}$ratio determination}

Monascus purpureus HJ11 strains were cultivated in GM medium at $30{ }^{\circ} \mathrm{C}$. Mycelia were collected after centrifugation and washed in PBS (50 mM, pH 7.0). Mycelia cells were lysed in base solution containing $1 \%(\mathrm{w} / \mathrm{v})$ dodecyl (trimethyl)azanium bromide. Then, $\mathrm{NADP}^{+}$and NADPH were individually detected according to NADP/NADPH$\mathrm{Glo}^{\mathrm{TM}}$ Assay (Promega, Southampton, UK) following the manufacturer's instructions.

\section{Batch and fed-batch fermentation}

The batch fermentation medium was as follows $(\mathrm{g} / \mathrm{L})$ : glucose 100, $\left(\mathrm{NH}_{4}\right)_{2} \mathrm{SO}_{4} 30, \mathrm{KH}_{2} \mathrm{PO}_{4} 10, \mathrm{Na}_{2} \mathrm{HPO}_{4}$, $\mathrm{MgSO}_{4} 0.5, \mathrm{CaCl}_{2} 0.5, \mathrm{ZnSO}_{4} \cdot 7 \mathrm{H}_{2} \mathrm{O} \quad 0.3, \mathrm{FeSO}_{4} \cdot 7 \mathrm{H}_{2} \mathrm{O}$ $0.3, \mathrm{CoSO}_{4} 7 \mathrm{H}_{2} \mathrm{O} 0.2, \mathrm{CuSO}_{4} \cdot 5 \mathrm{H}_{2} \mathrm{O} 0.2$, and $\mathrm{MnSO}_{4} \cdot \mathrm{H}_{2} \mathrm{O}$ $0.1 ; \mathrm{pH}$ 4.0. The seed culture was prepared by inoculating $10 \mathrm{~mL}$ of 5 -days pre-culture into $100 \mathrm{~mL}$ of GM medium in a $500-\mathrm{mL}$ flask and incubated at $30{ }^{\circ} \mathrm{C}$ and $120 \mathrm{rpm}$ for 7 days. The seed culture $(300 \mathrm{~mL})$ was transferred to a 10-L stirred tank bioreactor (Baoxing Bioengineering Equipment Co. Ltd, Shanghai, China) containing $6 \mathrm{~L}$ of fermentation medium. Fermentation was performed at $30{ }^{\circ} \mathrm{C}$ with an agitation speed of 50 to $200 \mathrm{rpm}$ and airflow rate of 1 to $2 \mathrm{vvm}$. The $\mathrm{pH}$ was maintained at 4.0 by automatic addition of $1.0 \mathrm{M} \mathrm{NaOH}$ solution.

Similarly, fed-batch fermentation medium was as follows $(\mathrm{g} / \mathrm{L})$ : glucose 100, $\left(\mathrm{NH}_{4}\right)_{2} \mathrm{SO}_{4} 50, \mathrm{KH}_{2} \mathrm{PO}_{4} 30$, $\mathrm{Na}_{2} \mathrm{HPO}_{4} 10, \mathrm{MgSO}_{4} 1.0, \mathrm{CaCl}_{2} 1.0, \mathrm{ZnSO}_{4} \cdot 7 \mathrm{H}_{2} \mathrm{O} 1.0$, $\mathrm{FeSO}_{4} \cdot 7 \mathrm{H}_{2} \mathrm{O} 0.5, \mathrm{CoSO}_{4} \cdot 7 \mathrm{H}_{2} \mathrm{O} 0.5, \mathrm{CuSO}_{4} \cdot 5 \mathrm{H}_{2} \mathrm{O} 0.3$, and $\mathrm{MnSO}_{4} \cdot \mathrm{H}_{2} \mathrm{O}$ 0.1. The seed culture and inoculation were performed similar to the batch fermentation, in a 10-L stirredtank bioreactor (Baoxing Bioengineering Equipment Co. Ltd, Shanghai, China) containing 6 L fermentation media. Fermentation was conducted at $30{ }^{\circ} \mathrm{C}$ with an agitation speed of 300 to $800 \mathrm{rpm}$ and an airflow rate of 1.5 to $2.5 \mathrm{vvm}$. $\mathrm{pH}$ was controlled at 4.0 by automatic addition of $\mathrm{NaOH}$ solution. After 4 days of fermentation, the residual glucose in medium was determined. When the residual glucose was below $5 \mathrm{~g} / \mathrm{L}$, a certain amount (about $300 \mathrm{~mL}$ ) of feed medium, containing $500 \mathrm{~g} / \mathrm{L}$ glucose, was added to the 10-L stirred tank bioreactor to maintain glucose concentration at $30 \mathrm{~g} / \mathrm{L}$ in the fermentation medium, and same amount of culture was withdrawn to analyze residual glucose concentration, biomass and MonAzPs concentration. 


\section{MonAzPs analysis}

Intercellular MonAzPs concentration was estimated following our previous method [29]. In this study, the concentration of MonAzPs was measured using UV-1700 spectrophotometer (Shimadzu, Tokyo, Japan) at specific wavelength of 410,470 , and $510 \mathrm{~nm}$ that corresponded to the characteristic absorbance of yellow, orange and red pigments, respectively. Total MonAzPs was calculated as the sum of yellow, orange, and red pigments. Statistical analysis was performed using Student's t-test [29].

\section{Gene knockout in M. purpureus HJ11}

Targeted gene knockout and complementation of $m r P D E$ in M. purpureus HJ11 was performed as described in our previous study [29].

\section{Data availability}

Sequences of the genes mentioned in this article are available in GenBank [29].

\section{Results and discussion}

Improvement in MonAzPs production and $m r P D E$ expression by exogenous CAMP addition

The effect of exogenous cAMP on M. purpureus HJ11 was evaluated. The MonAzPs production was determined under different concentrations $(0,1.0,2.0,3.0$ and $4.0 \mathrm{mM}$ ) of cAMP in GM medium. In the presence of exogenous cAMP, the strain showed higher MonAzPs yield (Fig. 2). At $2.0 \mathrm{mM}$ of cAMP concentration, maximum MonAzPs yield of $6065 \mathrm{U} / \mathrm{g}$ DCW was achieved, compared to the yield of $2606 \mathrm{U} / \mathrm{g}$ DCW without cAMP (Fig. 2a). This was consistent with a previous study, in which addition of $1.0 \mathrm{mM}$ exogenous cAMP promoted MonAzPs yield in M. ruber strain M7 [24]. In Fusarium graminearum, mycotoxin deoxynivalenol production was approximately increased by 40 -folds in cultures treated with $4 \mathrm{mM}$ cAMP [23]. The yields of red, orange, and yellow MonAzPs were $1812 \mathrm{U} / \mathrm{g}$ DCW, $1787 \mathrm{U} / \mathrm{g}$ DCW and $2466 \mathrm{U} / \mathrm{g}$ DCW, respectively (Fig. 2b-d). Among them, maximum rate of increase (179\%) was observed in the yield of yellow MonAzPs (Fig. 2d). These results indicated that the cAMP concentration played an important role in the growth and development of fungi and biosynthesis of secondary metabolites. Moreover, it was ascertained that
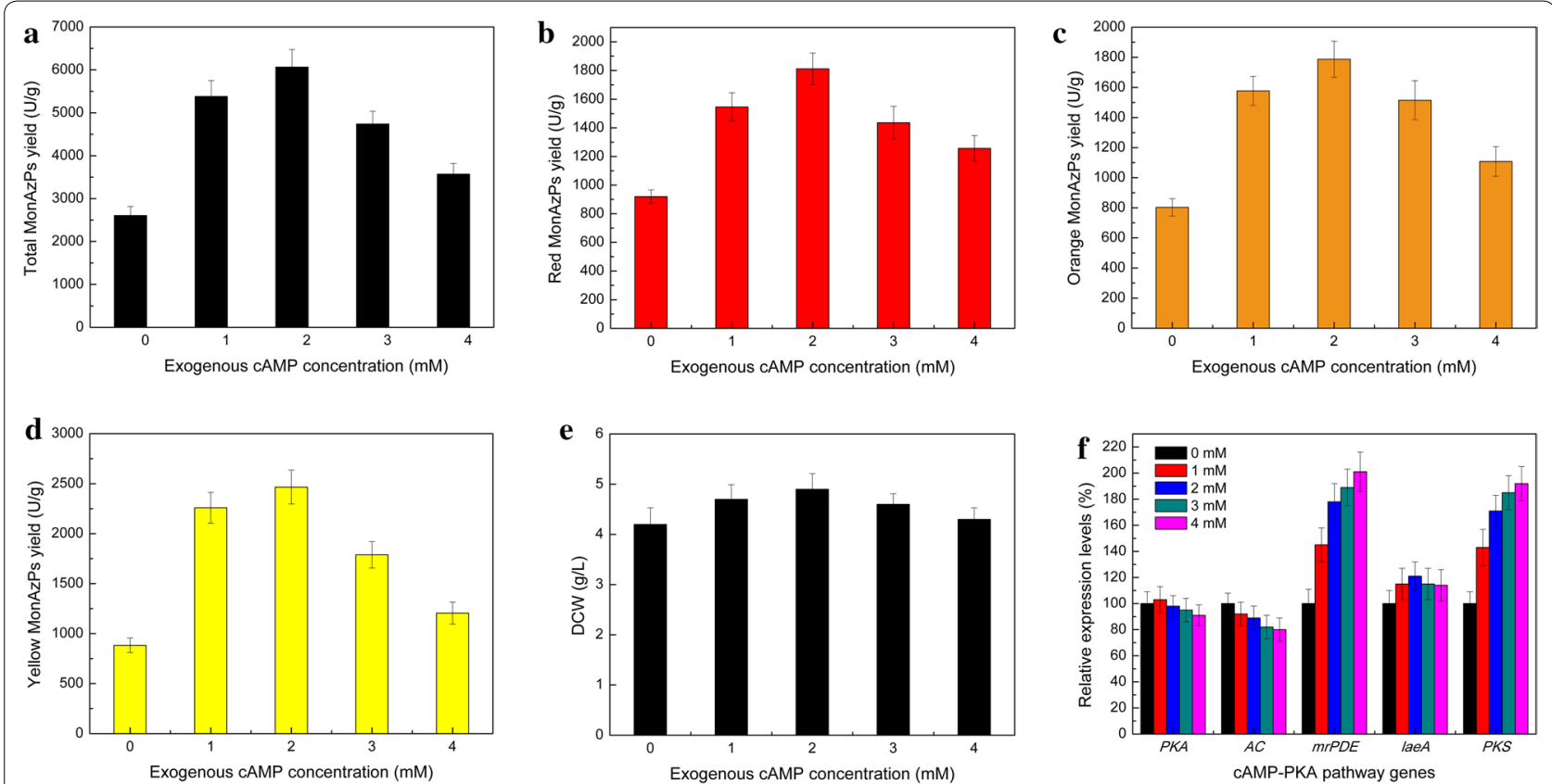

Fig. 2 Improvement in MonAzPs production by exogenous CAMP addition. Total MonAzPs (a), red MonAzPs (b), orange MonAzPs (b), and yellow MonAzPs (d) yields of M. purpureus HJ11 strain at different concentrations of exogenous CAMP in GM medium. e DCW of M. purpureus HJ11 strain in the presence of exogenous CAMP. Statistical analysis using Student's $t$-test revealed that there was a significant difference $(P<0.05)$ between groups $(0,1,2,3$ and $4 \mathrm{mM}$ ). f Relative transcription levels of protein kinase A (PKA), adenylate cyclase (AC), mrPDE, LaeA and polyketide synthase (PKS) genes on different exogenous CAMP concentrations. Three replicates were performed for this analysis. Student's t-test revealed a significant difference in relative expression levels of mrPDE and PKS genes between groups. Groups were not significantly different on PKA, AC and LaeA genes. Error bars represent standard deviations of three flasks 
the MonAzPs yield could be improved by increasing the concentration of cAMP.

When the concentration of cAMP was $2.0 \mathrm{mM}$, maximum dry cell weight (DCW) of $4.6 \mathrm{~g} / \mathrm{L}$ was achieved, while maximum DCW without cAMP was only $4.2 \mathrm{~g} / \mathrm{L}$ (Fig. 2e). Similar results were found in M. ruber strain M7 [24]. We evaluated the effects of exogenous cAMP on the transcription of genes relative in the cAMP-PKA pathway by quantitative reverse transcription-PCR (qRT-PCR) analysis. There were no marked changes in the expression levels of mrpigA and AC genes. The expression of global regulator gene laeA, which can regulate the MonAzPs biosynthetic gene cluster [14], was a little increased. The MonAzPs polyketide synthase gene mrpigA, which was responsible for MonAzPs precursor synthesis [29], showed an obvious increase in expression, explaining the improved production of MonAzPs. Unexpectedly, incubation with cAMP led to a strong induction of expression of a hypothetical PDE gene, named as $m r P D E$ (Fig. 2f and Additional file 1: Fig. S1). So, we speculated that this gene was responsible for negative regulation of cAMP in $M$. purpureus $\mathrm{HJ} 11$.

\section{Identification of MrPDE as a CAMP phosphodiesterase}

To the best of our knowledge, there was no report about PDE gene in Monascus spp. It was imperative to identify the PDE gene in M. purpureus HJ11. Comparison of the amino acid sequence of MrPDE with known sequences in the NCBI protein databases showed that a hypothetical PDE gene, XP_001264269.1 from Aspergillus fischeri, displayed the highest similarity of $64 \%$ with MrPDE. To further analyze MrPDE, several known PDEs (4OJV_A from S. cerevisiae, Q5AGE4 from Candida albicans, P12019 from Dictyostelium discoideum, and P36599 from Schizosaccharomyces pombe) were selected. A multiple alignment of 6 sequences mentioned above was also performed. The alignment analysis revealed two highly conserved amino acid motifs, which contained catalytic residues (Fig. 3a). This result indicated that MrPDE may be a fungal PDE.

a

M. ruber PDE

S. cerevisiae PDE1

101 LUTHPHLDHLAG

C. albicans $\mathrm{PDE}$

125 Y T THPHLDH I SG

D. discoideum PDE 167 F GHSHLDHVGG I

S. pombe PDE

A. fischeri $\mathrm{PDE}$ 167 L I THCHLDHY IG 101 L I THAHLDHSGG
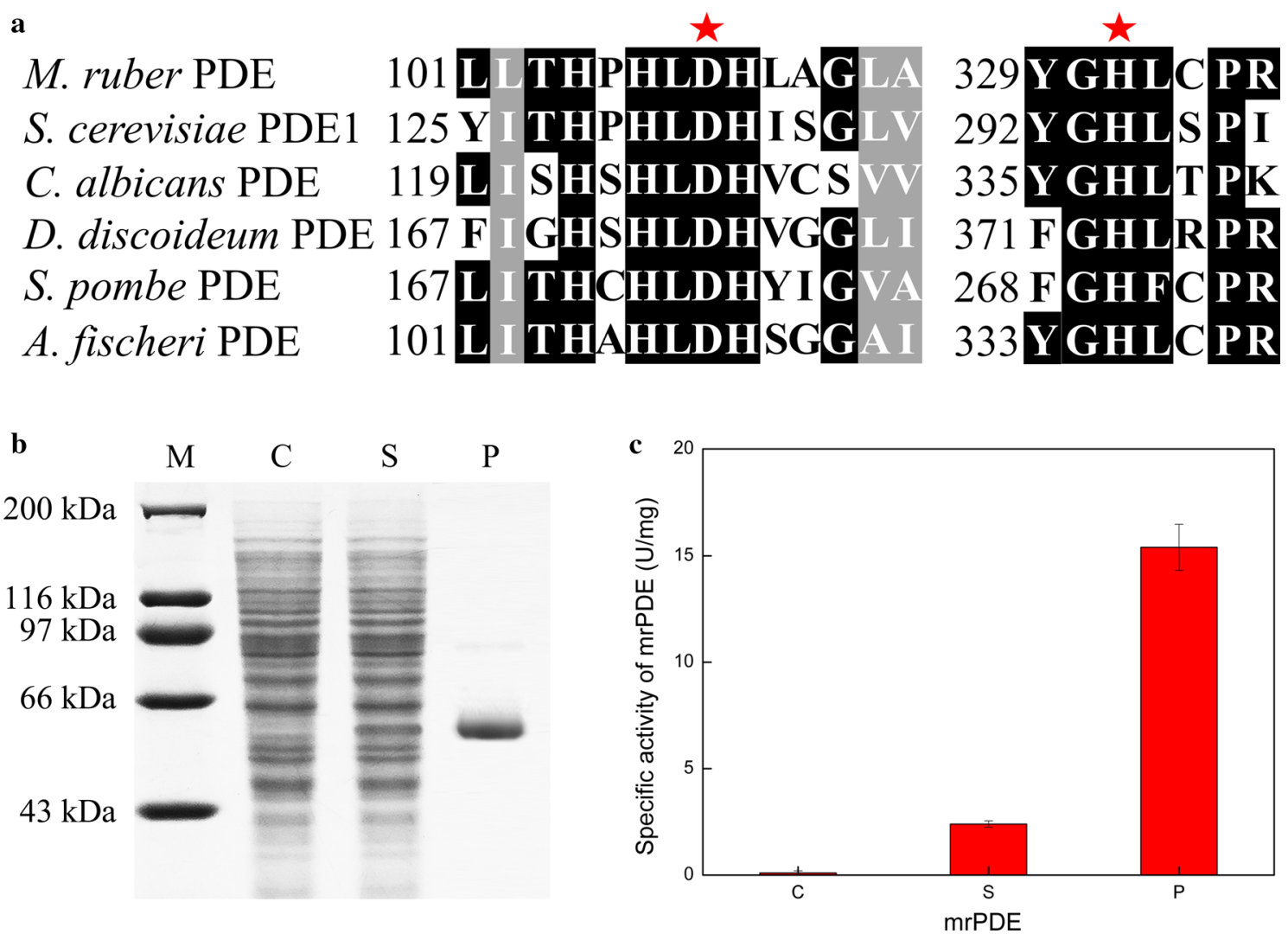

Fig. 3 3',5'-Cyclic nucleotide phosphodiesterase function of MrPDE. a Blocks of sequences conserved in MrPDE and several fungal PDEs. Pentagram indicates the possible catalytic amino acid residues. Identical amino acids are on a black background. $\mathbf{b}$ SDS-PAGE analysis and purification of MrPDE. M lane, protein marker; C lane, supernatant of E. coli BL21 (DE3) harboring control pET30a(+); S lane, supernatant of E. coli BL21 (DE3) containing pET30a(+)-mrPDE induced by IPTG; P lane, purified MrPDE protein. c Specific activity of MrPDE. The PDE activity of MrPDE was determined at $30^{\circ} \mathrm{C}$ in $50 \mathrm{mM}$ Tris-HCl buffer ( $\mathrm{pH}$ 8.0) using $3^{\prime}, 5^{\prime}$-cAMP as the substrate. Results were reported as mean value of three replicates \pm standard deviation 
To verify the function of MrPDE, the enzymatic activity was evaluated through in vitro reaction. MrPDE was heterologously expressed in E. coli BL21(DE3) strain. After induction with $0.5 \mathrm{mM}$ IPTG at $18{ }^{\circ} \mathrm{C}$ for $12 \mathrm{~h}$, SDS-PAGE analysis showed that MrPDE was successfully expressed in E. coli under the control of the T7 promoter (Fig. 3b, S lane). The enzyme was purified using Ni affinity chromatography column (Fig. 3b, P lane). The catalytic activity of MrPDE was determined with $3^{\prime}, 5^{\prime}$-cAMP as substrate. MrPDE was found to efficiently catalyze the hydrolysis of $3^{\prime}, 5^{\prime}$-cAMP (Fig. 3c). The specific activity of purified MrPDE was $15.4 \mathrm{U} / \mathrm{mg}$, which was close to that of PDE1 (20.5 U/mg) from S. cerevisiae S288C [33]. These results indicated that MrPDE was indeed a fungal PDE.

\section{Activation of CAMP signalling pathway by mrPDE knockout} To construct a MonAzPs high-producing strain, a $m r P D E$ gene knockout strain $\triangle m r P D E$ and a $m r P D E$ complemented knockout strain $C \triangle m r P D E$ were successfully engineered through homologous recombination technology. The colony diameter of $\triangle m r P D E$ was a little bigger than those of WT and C $\triangle m r P D E$, which indicated that the growth of $\triangle m r P D E$ strain was not inhibited by $m r P D E$ gene knockout (Fig. 4a). Meanwhile, the morphology of $\triangle m r P D E$ colonies grown on GM plate showed more intense color than those of WT and C $\triangle m r P D E$, implying that the $\triangle m r P D E$ strain might have a high production on MonAzPs (Fig. 4a).

The cAMP concentration was determined in each strain at different times. Notably, the cAMP concentration in $\triangle m r P D E$ strain was significantly higher than those of WT and $C \triangle m r P D E$ strains, attaining a maximum of $11,145 \mathrm{pmol} / \mathrm{g}$ on sixth day (Fig. 4b). The cAMP concentration in WT strain increased to $3219 \mathrm{pmol} / \mathrm{g}$ at the fourth day before gradually decreasing (Fig. 4b). Similar cAMP trend was observed in C $\triangle m r P D E$ strain. This result suggested that knockout of $m r P D E$ could inhibit the cAMP degradation, which led to a higher intracellular cAMP concentration. It has been reported that deletion of PDE gene in Ustilaginoidea virens and Magnaporthe oryzae both resulted in double-fold increase in cAMP concentration [21,34]. Thus, it was ascertained that deletion of PDE gene could efficiently increase cAMP concentration in M. purpureus HJ11.

In cAMP signalling pathway, PKA activity is essential for regulation of primary and secondary metabolism [35, 36]. Our data showed that knockout of $m r P D E$ could induce PKA kinase activity (Fig. 4c), suggesting the increase of cAMP concentration triggered PKA activation [37]. The DCW of $\triangle m r P D E$ strain reached $5.1 \mathrm{~g} / \mathrm{L}$, which was higher than those of WT $(4.2 \mathrm{~g} / \mathrm{L})$ and $C \triangle m r P D E$ strains $(4.2 \mathrm{~g} / \mathrm{L})$ (Fig. $4 \mathrm{~d})$. These results
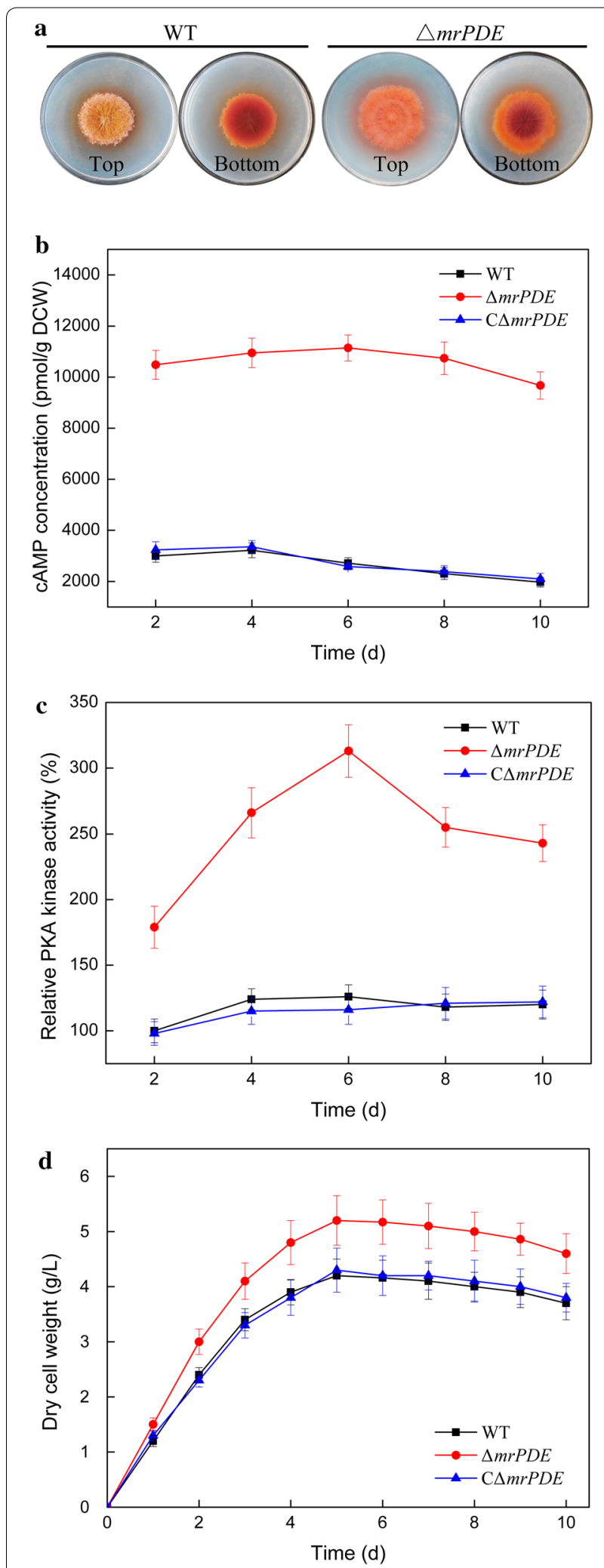

Fig. 4 Activation of CAMP signalling pathway by mrPDE knockout. a Colony morphology of WT and $\triangle M r P D E$ strains. The strains were cultivated on GM plates at $30^{\circ} \mathrm{C}$ for 10 days. The CAMP concentration (b), relative PKA kinase activity (c), and DCW (d) of WT, $\triangle m r P D E$ and $C \triangle m r P D E$ strains. Experiments were carried out in three replicates 
indicated that the cAMP signalling pathway was activated by knockout of $m r P D E$.

\section{Improvement of MonAzPs yield in $\triangle m r P D E$ strain}

For further confirmation of the MonAzPs production in $\triangle m r P D E$ strain, shake-flask fermentation was performed. After fermentation for 10 days, the MonAzPs yield of $\triangle m r P D E$ strain reached $8563 \mathrm{U} / \mathrm{g}$ DCW, which was 2.3 -fold higher than that of WT strain (Fig. 5). The yields of red, orange, and yellow pigments of $\triangle m r P D E$ strain were 2377, 2245 and $3941 \mathrm{U} / \mathrm{g}$ DCW, respectively (Fig. 5b-d). These yields were 1.58-times, 1.80-times, and 3.46-times higher than those of WT strain, respectively. The Monascus purpureus WT and $\triangle m r P D E$ strains were also cultivated in rice medium. The yields of red, orange, and yellow pigments in $\triangle m r P D E$ strain were 3721, 2655 and $4864 \mathrm{U} / \mathrm{g}$ DCW, respectively, which were higher than those of WT strain (2924, 2387 and $4059 \mathrm{U} / \mathrm{g}$ DCW). Similar study has been reported in F. graminearum, the knockout of PDE gene pde1 resulted in increased production of secondary metabolite deoxynivalenol [23].
The deletion of PDE gene $p d e H$ from $A$. flavus led to an increased production of aflatoxin to $110 \mathrm{mg} / \mathrm{mL}$ from $48 \mathrm{mg} / \mathrm{mL}$ [38].

To explain the reason of increasing MonAzPs yield, the expression of each genes from Monascus azaphilone pigments biosynthetic gene cluster (MPBGC) was determined by quantitative reverse transcription-PCR (qRTPCR) analysis. All MPBGC genes were expressed in the $\mathrm{WT}$ and $\triangle m r P D E$ strains. Unexpectedly, as shown by the $\triangle m r P D E$ strain, transcriptional activation of large parts of the genes in the MABGC was achieved, apart from mrpigH, mrpigI, mrpigL and mrpigP, which didn't participate in MonAzP biosynthesis (Additional file 1: Fig. S2) $[29,39]$. The downstream targets of PKA include transcriptional regulators and other effectors to control gene transcriptional expression [40]. These suggested that PKA, activated by cAMP, improved the transcriptional expression of MPBGC genes through indirect activation [41].

It is worth noting that the increased proportion of yellow MonAzPs yield was significantly higher than that
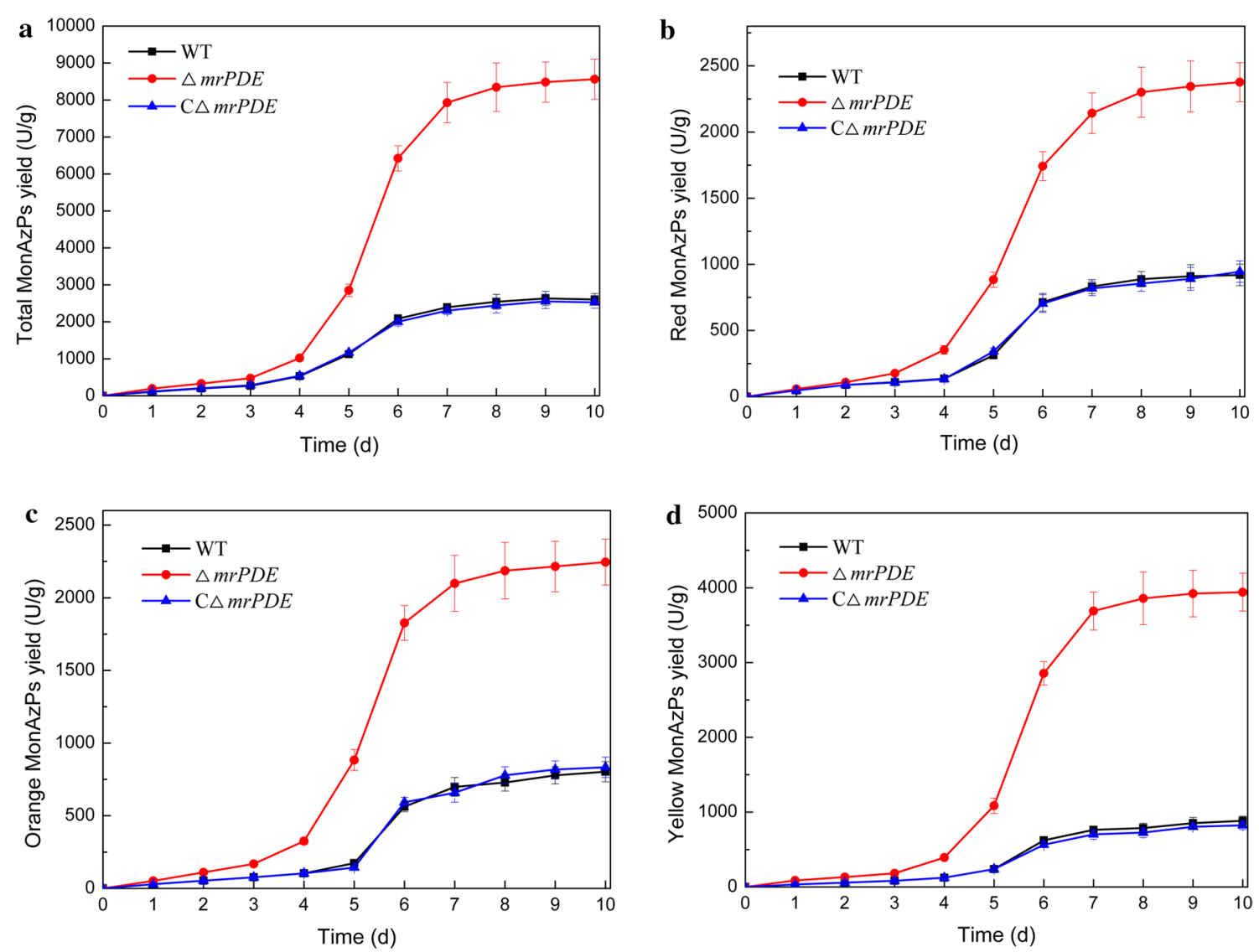

Fig. 5 Comparison of MonAzPs production between the WT, $\triangle m r P D E$, and $C \triangle m r P D E$ strains. Time courses of total MonAzPs (a), red MonAzPs (b), orange MonAzPs (c), yellow MonAzPs (d) production of WT, $\triangle m r P D E$ and C $\triangle m r P D E$ strains, respectively. The strains were cultivated in GM medium at $30^{\circ} \mathrm{C}$ for 10 days. The means and standard deviations calculated from measurements from three biological replicates for each strain were shown 
of total MonAzPs yield in $\triangle m r P D E$ strain (Figs. 2 and 5). In our previous study, orange MonAzPs were found to be converted into yellow MonAzPs in the presence of adequate NADPH [42]. So, it was speculated that the increased cAMP concentration led to higher rate of $\mathrm{NADPH} / \mathrm{NADP}^{+}$. There is little knowledge about the influence of cAMP on NADPH/NADP ${ }^{+}$rate in microorganism. Herein, it was found that the ratio in $\triangle m r P D E$ strain was 0.91 , which are much higher than those of WT and C $\triangle m r P D E$ strains (0.55 and 0.54, respectively) (Additional file 1: Fig. S3). This might be the main reason for the significantly higher yield of yellow MonAzPs than those of red and orange MonAzPs.

\section{High-density fermentation for high MonAzPs production}

In order to enhance the production of MonAzPs, batch fermentation of $\triangle m r P D E$ strain was performed in a medium, containing initial glucose concentration of $100 \mathrm{~g} / \mathrm{L}$. During the fermentation process, M. purpureus WT and $\triangle m r P D E$ strains formed pellet with an average diameter of $3.7 \pm 0.2 \mathrm{~mm}$. The formation of pellet contributed to pigments production. After 10 days of cultivation, total MonAzPs production reached a maximum of $158.9 \mathrm{U} / \mathrm{mL}$ (Fig. 6a), and corresponding total MonAzPs yield was $6782 \mathrm{U} / \mathrm{g}$ (Fig. 6b). However, this yield was lower than that in shake flask $(8563 \mathrm{U} / \mathrm{g})$. This might be attributed to the insufficient glucose supply $(<5 \mathrm{~g} / \mathrm{L})$ in the middle and later stages of fermentation, where mycelia accumulated the main part of MonAzPs (Fig. 6a).

For improvement of glucose supply, a fed-batch fermentation was also performed in a 10-L stirred fermenter [43]. The glucose solution was added in fermentation medium to maintain the glucose at $30 \mathrm{~g} / \mathrm{L}$ when residual glucose was below $5 \mathrm{~g} / \mathrm{L}$. The $\triangle m r P D E$ strain displayed rapid growth, and DCW reached $38.1 \mathrm{~g} / \mathrm{L}$, which was significantly higher than that of batch fermentation (Fig. 6c). In another study, fed-batch fermentation of Monascus anka strain GIM 3.592 achieved a DCW of $39.77 \mathrm{~g} / \mathrm{L}$ [44]. Subsequently, a significant increase in MonAzPs production was observed, reaching a maximum of 332.1 $\mathrm{U} / \mathrm{mL}$. The total MonAzPs yield reached $8739 \mathrm{U} / \mathrm{g}$ DCW, slightly higher than that in shake flask fermentation
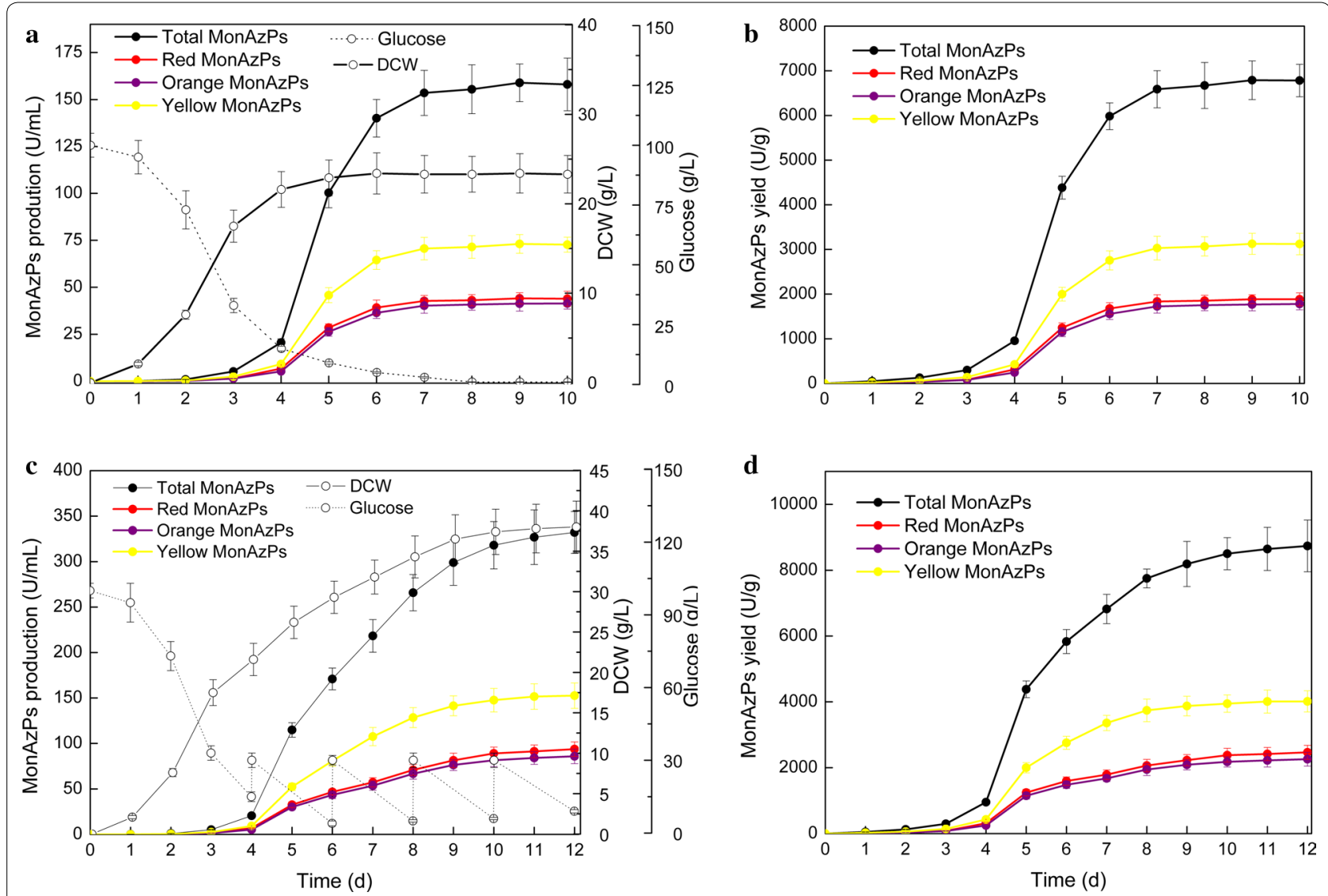

Fig. 6 MonAzPs production in batch and fed-batch fermentation using $\triangle m r P D E$ strain. Time course of cell growth, residual glucose and MonAzPs production during batch fermentation (a) and fed-batch fermentation (c). Patterns of MonAzPs yield in batch fermentation (b) and fed-batch fermentation (d). Data are presented as mean \pm SD from three independent experiments of three replicates each $(n=9)$ 
(Fig. 6d). It has been reported that a mutant M. purpureus strain M183 produced MonAzPs at $211.6 \mathrm{U} / \mathrm{mL}$ [15]. To the best of our knowledge, this study achieved highest MonAzPs yield and production.

\section{Conclusion}

In summary, $m r P D E$ was identified as a PDE from $M$. purpureus HJ11. Subsequently, knockout of the mrPDE gene was performed to enhance cAMP concentration. The MonAzPs yield in $\triangle m r P D E$ strain was achieved at $8563 \mathrm{U} / \mathrm{g}$, which was 2.3-folds higher than that of WT strain. In order to improve the MonAzPs production, the fed-batch fermentation was performed in a $10-\mathrm{L}$ stirred fermenter. The MonAzPs production was significantly enhanced to $332.1 \mathrm{U} / \mathrm{mL}$, with the MonAzPs yield of $8739 \mathrm{U} / \mathrm{g}$ DCW. This study describes a promising method for high production of MonAzPs and provides a strategy for metabolic engineering of secondary metabolism in other filamentous fungi.

\section{Supplementary Information}

The online version contains supplementary material available at https://doi. org/10.1186/s12934-020-01486-y.

Additional file 1: Fig. S1. Relative expression levels of mrPDE gene with or without $2.0 \mathrm{mM}$ CAMP during the cultivation. Error bars represent standard deviations of three flasks. Three replicates were performed for this analysis. Fig. S2. qRT-PCR analysis of the MPBGC genes of the M. purpureus HJ11 wild-type (WT) and $\triangle m r P D E$ knockout strains. Gene expression levels from WT strain are taken as the basis of comparison, with the means and standard deviations calculated from measurements from three biological replicates. Fig. S3. NADPH/NADP + ratio analysis of M. purpureus HJ11 WT and $\triangle m r P D E$ knockout strains. NADP + and NADPH were individually detected. The NADPH/NADP + ratio was calculated with NADP+ and NADPH levels.

\section{Acknowledgements}

Not applicable.

\section{Authors' contributions}

$J, Y$ and $X P$ designed the experiments. $J$ and $Y D$ carried out the majority of experimental work and analyzed the results. HM and ML drafted the manuscript. XP revised the manuscript. JL and YD contributed equally to this study. All authors read and approved the final manuscript.

\section{Funding}

This work was supported by the National Natural Science Foundation of China (31871780 to M.L), the Fundamental Research Funds for the Central Universities (No. 2662018PY059 to M.L. and No. 2019 BC014 to J.L).

\section{Availability of data and materials}

The datasets used and analyzed during the current study are available from the corresponding author on reasonable request.

\section{Ethics approval and consent to participate}

Not applicable.

\section{Consent for publication}

All authors have approved publication of the manuscript.

\section{Competing interests}

The authors declare that they have no competing interests.

\section{Author details}

${ }^{1}$ Hubei International Scientific and Technological Cooperation Base of Traditional Fermented Foods, Key Laboratory of Environment Correlative Dietology, College of Food Science and Technology, Huazhong Agricultural University, Hubei Province, Wuhan 430070, China. ${ }^{2}$ Key Laboratory of Combinatorial Biosynthesis and Drug Discovery Ministry of Education, School of Pharmaceutical Sciences, Wuhan University, Wuhan 430071, China. ${ }^{3}$ College of Material, Chemistry and Chemical Engineering, Hangzhou Normal University, Hangzhou 310012, China.

Received: 5 August 2020 Accepted: 28 November 2020

Published online: 07 December 2020

\section{References}

1. Liu L, Zhao J, Huang Y, Xin Q, Wang Z. Diversifying of chemical structure of native Monascus pigments. Front Microbiol. 2018;9:3143.

2. Wakai S, Arazoe T, Ogino C, Kondo A. Future insights in fungal metabolic engineering. Bioresour Technol. 2017;254:1314-26.

3. Chen W, Feng Y, Molnar I, Chen F. Nature and nurture: confluence of pathway determinism and metabolic serendipity diversifies Monascus azaphilone pigments. Nat Prod Rep. 2019;36:561-72.

4. Babitha S, Soccol CR, Pandey A. Solid-state fermentation for the production of Monascus pigments from jackfruit seed. Bioresour Technol. 2007;98:1554-60.

5. Liu J, Chai X, Guo T, Wu J, Yang P, Luo Y, Zhao H, Zhao W, Nkechi O, Dong J, Bai J, Lin Q. Disruption of the ergosterol biosynthetic pathway results in increased membrane permeability, causing overproduction and secretion of extracellular Monascus pigments in submerged fermentation. J Agric Food Chem. 2019;67:13673-83.

6. Yang Y, Liu B, Du XJ, Li P, Liang B, Cheng XZ, Du LC, Huang D, Wang L, Wang S. Complete genome sequence and transcriptomics analyses reveal pigment biosynthesis and regulatory mechanisms in an industrial strain, Monascus purpureus YY-1. Sci Rep. 2015;5:8331-9.

7. Patakova P. Monascus secondary metabolites: production and biological activity. J Ind Microbiol Biotechnol. 2013;40:169-81.

8. Zheng Y, Zhang Y, Chen D, Chen H, Lin L, Zheng C, Guo Y. Monascus pig ment rubropunctatin: a potential dual agent for cancer chemotherapy and phototherapy. J Agric Food Chem. 2016;64(12):2541-8.

9. Shi YC, Pan TM, Liao VHC. Monascin from Monascus-fermented products reduces oxidative stress and amyloid- $\beta$ toxicity via DAF-16/FOXO in Caenorhabditis elegans. J Agric Food Chem. 2016;64(38):7114-20.

10. Jongrungruangchok S, Kittakoop P, Yongsmith B, Bavovada R, Tanasupawat S, Lartpornmatulee N, Thebtaranonth Y. Azaphilone pigments from a yellow mutant of the fungus Monascus kaoliang. Phytochemistry. 2004;65(18):2569-75.

11. Huang T, Tan HL, Lu FJ, Chen G, Wu ZQ. Changing oxidoreduction potential to improve water-soluble yellow pigment production with Monascus ruber CGMCC 10910. Microb Cell Fact. 2017;16:208.

12. Lv J, Zhang BB, Liu XD, Zhang C, Chen L, Xu GR, Cheung PCK. Enhanced production of natural yellow pigments from Monascus purpureus by liquid culture: the relationship between fermentation conditions and mycelial morphology. J Biosci Bioeng. 2017;124:452-8.

13. Long C, Zeng X, Xie J, Liang Y, Tao J, Tao Q, Liu M, Cui J, Huang Z, Zeng B. High-level production of Monascus pigments in Monascus ruber CICC41233 through ATP-citrate lyase overexpression. Biochem Eng J. 2019;146:160-9.

14. Liu Q, Cai L, Shao Y, Zhou Y, Li M, Wang X, Chen F. Inactivation of the global regulator LaeA in Monascus ruber results in a species-dependent response in sporulation and secondary metabolism. Fungal Biol. 2016;120:297-305.

15. Liu J, Guo T, Luo Y, Chai X, Wu J, Zhao W, Jiao P, Luo F, Lin Q. Enhancement of Monascus pigment productivity via a simultaneous fermentation process and separation system using immobilized-cell fermentation. Bioresour Technol. 2019;272:552-60.

16. Hu Y, Liu Y, Hao X, Wang D, Akhberdi O, Xiang B, Zhu X. Regulation of the Ga-cAMP/PKA signaling pathway in cellulose utilization of Chaetomium globosum. Microb Cell Fact. 2018;17:160-72. 
17. Hall RA, Mühlschlegel FA. A multi-protein complex controls CAMP signalling and filamentation in the fungal pathogen Candida albicans. Mol Microbiol. 2010;75(3):534-7.

18. Guo L, Breakspear A, Zhao G, Gao L, Kistler HC, Xu J, Ma L. Conservation and divergence of the cyclic adenosine monophosphate-protein kinase A (CAMP-PKA) pathway in two plant-pathogenic fungi: Fusarium graminearum and F. verticillioides. Mol Plant Pathol. 2016;17(2):196-209.

19. Mirzadi GA, Mehrabi R, Robert O, Ince IA, Boeren S, Schuster M, Steinberg G, de Wit PJGM, Kema GHJ. Molecular characterization and functional analyses of ZtWor1, a transcriptional regulator of the fungal wheat pathogen Zymoseptoria tritici. Mol Plant Pathol. 2014;15(4):394-405.

20. Kumar V, Hart AJ, Wimalasena TT, Tucker GA, Greetham D. Expression of RCK2 MAPKAP (MAPK-activated protein kinase) rescues yeast cells sensitivity to osmotic stress. Microb Cell Fact. 2015;14:85-94.

21. Ramanujam R, Naqvi NI. PdeH, a high-affinity cAMP phosphodiesterase, is a key regulator of asexual and pathogenic differentiation in Magnaporthe oryzae. PLoS Pathog. 2010;6:e1000897.

22. Brakhage AA, Liebmann B. Aspergillus fumigatus conidial pigment and CAMP signal transduction: significance for virulence. Med Mycol. 2005;43(Suppl. 1):S75-82.

23. Jiang C, Zhang C, Wu C, Sun P, Hou R, Liu H, Wang C, Xu J. TRI6 and TRI10 play different roles in the regulation of deoxynivalenol (DON) production by CAMP signaling in Fusarium graminearum. Environ Microbiol. 2016;18:3689-701.

24. Lai Y, Wang L, Qing L, Chen FS. Effects of cyclic AMP on development and secondary metabolites of Monascus ruber M-7. Lett Appl Microbiol. 2011;52:420-6.

25. Cardarelli S, Giorgi M, Naro F, Malatesta F, Biagioni S, Saliola M. Use of the KIADH3 promoter for the quantitative production of the murine PDE5A isoforms in the yeast Kluyveromyces lactis. Microb Cell Fact. 2017:16:159-70

26. Studt L, Humpf HU, Tudzynski B. Signaling governed by G proteins and CAMP is crucial for growth, secondary metabolism and sexual development in Fusarium fujikuroi. PLoS ONE. 2013;8(2):e58185.

27. Macheleidt J, Mattern DJ, Fischer J, Netzker T, Weber J, Schroeckh V, Valiante V, Brakhage AA. Regulation and role of fungal secondary metabolites. Annu Rev Genet. 2016;50:371-92.

28. Li X, Liu Y, Tan X, Li D, Yang X, Zhang X, Zhang D. The high-affinity phosphodiesterase PCPdeH is involved in the polarized growth and pathogenicity of Phytophthora capsici. Fungal Biol. 2020;124:164-73.

29. Li M, Kang L, Ding X, Liu J, Liu Q, Shao Y, Molnár I, Chen FS. Monasone naphthoquinone biosynthesis and resistance in Monascus fungi. mBio. 2020;1:e02676-19.

30. Guo HL, Zhang Y, Shao YC, Chen WP, Chen FS, Li M. Cloning, expression and characterization of a novel cold active and organic solvent tolerant esterase from Monascus ruber M7. Extremophiles. 2016;26:451-9.

31. Röhrig T, Liesenfeld D, Richling E. Identification of a phosphodiesteraseinhibiting fraction from roasted coffee (Coffea arabica) through activityguided fractionation. J Agric Food Chem. 2017;65:3792-800.
32. Carrasco-Navarro U, Vera-Estrella R, Barkla BJ, Zúñiga-León E, Reyes-Vivas $H$, Fernández FJ, Fierro F. Proteomic analysis of the signaling pathway mediated by the heterotrimeric Ga protein Pga1 of Penicillium chrysogenum. Microb Cell Fact. 2016;15:173-89.

33. Tian Y, Cui W, Huang M, Robinson H, Wan Y, Wang Y, Ke H. Dual specificity and novel structural folding of yeast phosphodiesterase-1 for hydrolysis of second messenger's cyclic adenosine and guanosine $3^{\prime}, 5^{\prime}$-monophosphate. Biochemistry. 2014;53:4938-45.

34. Guo WW, Gao YY, Yu ZM, Xiao YH, Zhang ZG, Zhang HF. The adenylate cyclase UvAc1 and phosphodiesterase UvPdeH control the intracellular cAMP level, development, and pathogenicity of the rice false smut fungus Ustilaginoidea virens. Fungal Genet Biol. 2019;129:65-73.

35. Musheshe N, Schmidt M, Zaccolo M. cAMP: From long-range second messenger to nanodomain signalling. Trends Pharmacol Sci. 2018;39(2):209-22.

36. Hu Y, Liu Y, Hao X, Wang D, Akhberdi O, Xiang B, Zhu X. Regulation of the Ga-CAMP/PKA signaling pathway in cellulose utilization of Chaetomium globosum. Microb Cell Fact. 2018;17(1):160.

37. Koschinski A, Zaccolo M. Activation of PKA in cell requires higher concentration of CAMP than in vitro: implications for compartmentalization of cAMP signalling. Sci Rep. 2017;7:14090.

38. Yang K, Liu Y, Liang L, Li Z, Qin Q, Nie X, Wang S. The high-affinity phosphodiesterase PdeH regulates development and aflatoxin biosynthesis in Aspergillus flavus. Fungal Genet Biol. 2017;101:7-19.

39. Bijinu B, Suh JW, Park SH, Kwon HJ. Delineating Monascus azaphilone pigment biosynthesis: oxidoreductive modifications determine the ring cyclization pattern in azaphilone biosynthesis. RSC Adv. 2014;4:59405-8.

40. Huang G, Huang Q, Wei Y, Wang Y, Du H. Multiple roles and diverse regulation of the Ras/CAMP/protein kinase A pathway in Candida albicans. Mol Microbiol. 2019;111(1):6-16.

41. Cao C, Wu M, Bing J, Tao L, Ding X, Liu X, Huang G. Global regulatory roles of the CAMP/PKA pathway revealed by phenotypic, transcriptomic and phosphoproteomic analyses in a null mutant of the PKA catalytic subunit in Candida albicans. Mol Microbiol. 2017;105(1):46-64.

42. Chen W, Chen R, Liu Q, He Y, Kang L, Guo X, Xie N, Zhou Y, Lu Y, Cox RJ, Molnár I, Li M, Shao Y, Chen F. Orange, red, yellow: biosynthesis of azaphilone pigments in Monascus fungi. Chem Sci. 2017;8:4917-25.

43. Swart RM, Le Roux F, Naude A, de Jongh NW, Nicol W. Fumarate production with Rhizopus oryzae: utilising the Crabtree effect to minimise ethanol by-product formation. Biotechnol Biofuels. 2020;13(1):22-31.

44. Chen G, Shi K, Song D, Quan L, Wu Z. The pigment characteristics and productivity shifting in high cell density culture of Monascus anka mycelia. BMC Biotechnol. 2015;15:72-80.

\section{Publisher's Note}

Springer Nature remains neutral with regard to jurisdictional claims in published maps and institutional affiliations.

\footnotetext{
Ready to submit your research? Choose BMC and benefit from:

- fast, convenient online submission

- thorough peer review by experienced researchers in your field

- rapid publication on acceptance

- support for research data, including large and complex data types

- gold Open Access which fosters wider collaboration and increased citations

- maximum visibility for your research: over $100 \mathrm{M}$ website views per year
}

At BMC, research is always in progress.

Learn more biomedcentral.com/submissions 